\title{
Communicating Information Society Related RTD and Deployment Results in Support of EU Public Policies
}

\author{
Vasileios Laopodis \\ InnoPolis: Centre for Innovation and Culture \\ International non-profit organization, Athens, Greece \\ vasileios.laopodis@gmail.com, http://www.innopolis.org
}

\begin{abstract}
The aim of this paper is to discuss issues related to communication and exploitation of Information Society related project results emanating from RTD and deployment projects funded by EU programmes such as IST programme, eTen, eContent and eContent plus etc. In particular it will examine how these results may impact other major EU policies e.g. public health, environment, education etc. First, it presents the different EU programmes and initiatives aiming at greater economic growth, sustainable development and social cohesion through ICTs and their pervasive role in economy and society. Then it discusses the role that communication of RTD results may have on transferring knowledge, influencing action and more important creating public appreciation of the benefits obtained. To illustrate this dimension it presents in detail the 'Information Society Policy Link' initiative of Information Society and Media DirectorateGeneral (DG INFSO) and its first collection of successful project results (policy cases) having positively impacted different EU policy areas and in particular Environmental policies. Finally it draws some conclusions regarding the inclusion of such approaches for effective dissemination of research and deployment results in the EU funded programmes as well as in national initiatives.
\end{abstract}

Keywords: Information Society Policy Link; ICTs; Information Society; RTD policy making; Environment

\section{From RTD Results to Policy Making: the Case of ICT}

Information and Communication Technologies (ICTs) are of crucial importance for Europeans. They are 'breakthrough technology', similar to the steam engine and electricity, that will have a major impact on how we live and work over the next century. They are therefore fundamental to achieving the EU's 'Lisbon goal' of greater

Please use the following format when citing this chapter:

Laopodis, V, 2006, in IFIP International Federation for Information Processing, Volume 223, Social Informatics: An Information Society for All? In Remembrance of Rob Kling, eds. Berleur, J., Numinen, M. I., Impagliazzo, J., (Boston: Springer), pp. 195-207. 
economic growth, sustainable development and social cohesion. Consequently, the European Union devotes considerable effort to Information Society related actions.

For instance, Information Society Technologies (IST) research programme [1] has been the largest thematic priority in the EU's Fifth (1998-2002) and Sixth (2002-2006) Framework Research Programmes. Together they represent an investment of over $€ 7 \mathrm{bn}$ in IST research, and are complemented by programmes such as eContent $(€ 100 \mathrm{~m})$ and eTen $(€ 315 \mathrm{~m})$, which focus on digital content and eServices deployment respectively. A range of policies also aims to ensure that Europe exploits the possibilities offered by the Information Society. The main components are: eGovemment, eHealth, elnclusion, eLearning, eBusiness, Security - cyber crime, Broadband, eSafety, Safer Internet Programme.

Fig. 1 Integrated process for assessing and disseminating RTD and deployment EU funded results in the area of Information Society and Media.

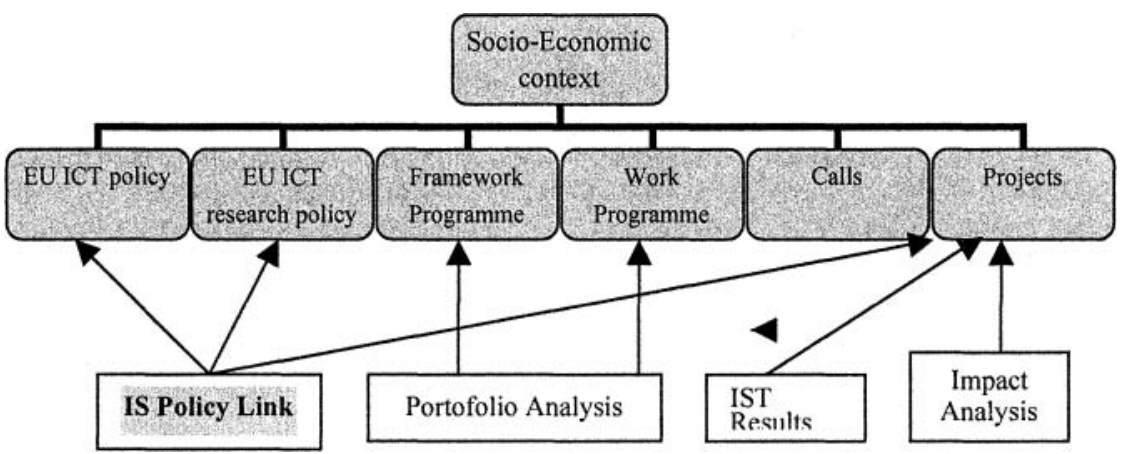

The projects funded by these programmes offer benefits to all areas of Europe's economy and society. To fully realize these benefits, the technologies on the one hand, need to be linked closely to European policy-making in the relevant areas, and on the other ensure that the results are used as quickly as economically justifiable for the benefit of EU citizens and the EU economy. Effective communication is essential, both in transferring knowledge and influencing action.

On the other hand there is a need to ensure that the flow of R\&D funding is sustained by creating public appreciation of the benefits obtained. Such an action also demands effective communication to help recipients become aware about new technological breakthroughs facilitating our life but also about potential dangers and ways to prevent from possible negative effects.

Passing the right message to the right people: For each of these objectives there is a need for a professional approach for a communication strategy. This strategy will analyse the target audiences and communication channels and it will define appropriate sub-objectives, communication messages, and techniques. In our view current efforts do not address these issues adequately.

The diverse nature of the R\&D projects supported within the Framework Programmes means that different projects require different approaches. While some projects will produce results that are quickly obvious to end users in products or services, others will mainly affect industrial or commercial processes or components. Communication strategies need to take account of these differences and different 
target groups and stakeholders: networks, clusters and EU industrial groupings as well as the public.

Similarly, fostering public appreciation is not a task for which a single 'one size fits all' approach should be expected. Different types of result are impressive for different groups, and the diffusion of attitudes within a population operates differently both for different ideas and for different cultures. The existing state of public opinion is also a factor to be taken into account when devising strategies, and this will introduce inter-country differences.

We feel that applications of EU R\&D results, creating networks and leading to products and services that are in wide public use, represent an area in which strategies for uptake and strategies for public appreciation can overlap. This needs to be investigated to determine the full scale of the opportunity.

There is scope for both direct promotion and influencing and for indirect action, allowing the message to become apparent through the actions of third parties. The underlying perception is that citizens who are alerted to the developments which the EU R\&D programmes are aiming at - and are delivering as time goes on - will be affected in three key ways:

- by coming to appreciate the case for EU R\&D

- by exerting market pull which speeds up the adoption of future developments

- by generating a constituency for the adoption of Framework Programme results by Commission policy departments

\section{Integrated Process for Disseminating ICT Research and Deployment Results}

The study and close monitoring of research and deployment projects results has always been an important issue for policy makers in Information Society. At EU level and in particular in the Information Society and Media DG, a fully integrated process has been developed by the strategy and policy for ICT research unit (DG INFSO C.2) with main components the following projects and framework contracts: Integrated Programme Portfolio Analysis (IPPA); Impact Analysis. On the other hand there exist initiatives focusing on broader dissemination and reinforcing exploitation of ICT related research and deployment activities, notably: IST Results [2]; and in 2004 the Information Society Policy Link initiative [3].

Figure 1 presents the framework for such synergies and the level of intervention of each one of them.

\subsection{IST Results: Key Part of an Integrated Process}

The objective of this approach is to seek for synergies among these actions.

- Impact Analysis is an ex-post assessment of programme/projects results for families of programmes / projects e.g. IST, Esprit IV, ACTS and TAP) in one or more particular areas e.g. 'Health Applications' 'Mobile Communications and Systems' and 'Microelectronics and Microsystems'.

- IPPA is an analysis of the focus of the different RTD projects as they are launched) are part of a complementary set of activities contributing to strategic analysis and communication while IPPA is a rolling process which can also contribute to development of synergies within the IST Programme. 
- IST Results is an online editorial service whose objectives are to raise the visibility of IST-funded research results, to support projects' access to markets and encourage uptake of innovations, and to raise awareness of the IST Programme and its activities.

For achieving this goal IST Results initiative has a number of deliverables to different target audiences: Feature Articles on specific FP5 and FP6 IST projects, Regular News in Brief on ICT-related topics, Weekly E-Bulletin / customisable Email Alerts, Events Calendar covering IST project events, Dedicated Press Desk and Investors Room, Syndicated content via press wires and RSS.

Target Audiences vary from:

- New Technology Users (enterprises of all sizes, public authorities)

- Intermediaries / Information Relays

- Investors / Technology Brokers

- Research Community

- Press / Media, and,

- Internal EU audiences (POs, IST projects, other DGs).

\subsection{Looking for Synergies}

There are several links among the above initiatives and projects, which can be summarised as follows:

- IPPA and IST Results provide an essential input to Impact Analysis

- IST Results can carry out data collection and editing which is essential both for the dissemination of results (current IST Results) and IS Policy Link initiative

- IPPA and Impact Analysis should be more 'rigorous' and systematic while IST Results and IS Policy Link can be more punctual and more focused on success stories and showcases within a strong PR perspective

- IPPA, IST Results, IS Policy Link and Impact Analysis contribute together to the development of EU ICT research policy

\section{Information Society Policy Link}

\subsection{Description of the Initiative}

Information Society promises potentially significant benefits throughout Europe's economy and society. These benefits will not be realized completely, however, if the technologies are not linked closely to European policymaking in the relevant areas.

Among the numerous EU awareness raising and promotions actions regarding ICT research and its impact the Information Society Policy Link initiative [3] of Information Society \& Media DG to identify and reinforce links between its projects and relevant EU policies launched in 2004, is linking Information Society projects with relevant European policies as diverse as environmental protection, security and public health [1].

Hence 'Information Society Policy Link' where these cutting-edge projects are connected to the relevant policies, helping Europe both better implements today's policies and ensure that policy development takes the possibilities offered by ICTs into account.

This is a targeted initiative to EU Policy Makers started mid 2004 with the aim to improve co-operation between DG Information Society and Media and all other policy DGs, EU institutions as well as Public Administrations in Member States. 
The approach selected is to proceed to by linking projects results from INFSOfunded actions (e.g. IST, eTen, eContent) to EU policy makers, thereby bringing together the major stakeholders.

Fig.2 The Information Society Policy Link multipartite collaboration

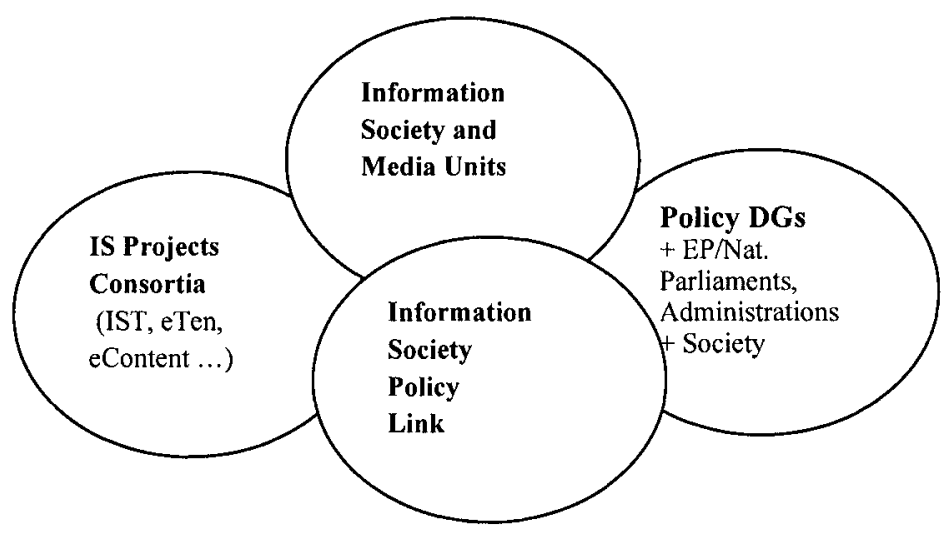

The Figure 2 illustrates the multipartite collaboration where all main actors such as EU policy makers; INFSO Units; INFSO funded projects consortia (under programmes such as: Information Society Technology - IST, European Trans European Networks - eTen, Digital Content (eContent and eContentplus) are involved with major beneficiaries EC policy DGs/services (main target), other EU institutions (in particular EP), Agencies National Parliaments \& Member States administrations.

\subsection{Impact of ICT Research Projects on Other EU Policy Areas}

The pilot phase of this initiative ended in June 2005 identified $\sim 200$ Policy Cases (promising projects) grouped in six categories covering 20 European Union Policy Areas

European Society: Culture \& Multilingualism; Education; Employment \& Social Affairs; Health; E-Inclusion

Governance: E-Government \& E-Democracy; Regional Policy; Security \& Justice; Sustainable Development; Environment; Energy \& Transport; Agriculture \& Fisheries

Competitiveness: Enterprise Policy; Industrial Policy; Single Market

Research \& Innovation: Information Society; Research \& Technology; Standardization

International Relations: International Community; (External Trade, External Relations, Development, Humanitarian Aid)

To demonstrate the impact of DG Information Society and Media funded ICT research and development projects on specific EU public policies we discuss below the case of EU environmental policy where ICTs could be used for policy purposes. 


\section{Impact of ICTs on other EU Polices: The Case of Environmental Policy}

\subsection{Challenges for the Environment}

Environment constitutes one of the major EU policy priorities. Protecting our environment is essential for the quality of life of current and future generations. While environmental protection is not synonymous with sustainable development, it is a key component and serves to emphasize the fact that environmental considerations should be an integral part of other policy objectives in areas such as competitiveness, innovation, inclusion, health and security. Access to and exploitation of high-quality information is essential to our ability to safeguard the environment. There is paradox here in that many environmental theories, assumptions and models are currently based on very limited amounts of data. Better identification and exploitation of environmental data sources is a prosperous field for ICTs applications for improving our understanding of the environment.

Management of natural resources presents another key challenge. It is widely recognised that the current pace of world population and economic growth cannot be sustained. The combination of resource exhaustion and pollution threaten widespread degradation of our physical environment. The gross inequality of wealth distribution, where $20 \%$ of the world's population consumes $80 \%$ of its resources, is also unsustainable because of the tensions and threats it raises for global security. We need to address both the absolute increases in resource consumption and the relative inequalities between the developed and developing worlds.

The Information Society has been playing an important role in environmental protection and sustainable development. New technologies and organisational structures will reduce the environmental impact of industry and society, improve our understanding of our environment and provide us with the information we need to protect our world for future generations.

Sustainable development has been a central EU priority for several years and was articulated in an EU strategy agreed at the Göthenburg Summit in June 2001. Since then, environmental protection and sustainable development have been 'mainstreamed' throughout the EU's policies and activities.

The cornerstone of the EU's environmental policy is Environment 2010: Our Future, Our Choice, and the EU's Sixth Environment Action Programme [4] covering the period 2001-2010. The Programme identifies four thematic priorities to be tackled over the current decade:

- Climate change;

- Nature and biodiversity;

- Environment, health and quality of life;

- Natural resources and waste.

\subsection{Where the Information Society Meets the Environment}

The 6th Environmental Action Programme provides the environmental component of the Community's sustainable development strategy, placing the EU's environmental plans in a broad perspective, considering economic and social conditions. It also makes the link between environment and European objectives for growth and competitiveness.

To further focus stakeholders' efforts, seven thematic strategies have been developed, each following a common and incremental approach towards policy action 
and proposals. These thematic strategies cover: air pollution; soil protection; protection and conservation of the marine environment; sustainable use of pesticides; urban environment; sustainable use of natural resources; and waste recycling.

The Information Society can support these goals in many ways, providing key building blocks for putting the sustainable development principle into action. Connecting cutting-edge Information Society projects to relevant environmental policies will therefore both help Europe meet its environmental and sustainability goals and stimulate growth and innovation. A wide range of EU policies and activities are already applying Information Society technologies to help us better understand our environment and how we are affecting it.

Good communications and IT support also play a life-saving role in crisis management.

Key initiatives are:

- Galileo: a satellite navigation system being supported jointly by the European Union and the European Space Agency (ESA), which will have a substantial impact on our understanding of the environment as well as contribute to other sectors such as agriculture, fisheries and transport.

- Global Monitoring for Environment and Security (GMES): another joint initiative between the EU and ESA to strengthen the acquisition and integration of highquality EU environmental, geographical and socio-economic data. It will help improve policymaking from local to global level.

- INfrastructure for SPatial InfoRmation in Europe (INSPIRE): an initiative of the European Commission with Member States to improve access to high quality geospatial information.

Under Framework Programme 6, IST research activities in the field of environmental applications focus on the management of environmental risk due to natural hazards, industrial accidents or civil security events. Activities cover two phases: the first one covering the monitoring, planning, forecasting, preparedness and recovery phases; and the second dealing mainly with the alert and response phase. ICT for Environmental Risk Management constitute an important action whose objectives are:

(i) to improve risk planning and forecasting by the development of harmonised geospatial information to maintain vulnerability information and allow for managing interrelated risks (domino effects)

(ii) to improve the crisis management operation by addressing the interoperability of civil protection equipment allowing for joint intervention in case of major disasters, and

(iii) to develop new approaches for the deployment of in-situ sensor networks and bridge the gap between in situ and remote sensing observation in the context of the Global Monitoring for Environment and Security initiative and of the proposed INPIRE directive.

Key technology areas being addressed in the research include:

- Sensors with communication and location capabilities;

- Tools for modelling, simulation, decision support and visualisation, including integration of geo-spatial data;

- Service architectures and platforms for environmental and crisis management based on open standards. Interoperability of equipment and systems is a key concern in this field. IST research promotes the development of open platforms that support the evolution towards network-centric environmental and crisis management solutions. 
Environmental applications can also be found in other Information Society and Media funded Activities such as a) the eTEN Programme, primarily for the practical realisation of eEurope's objectives on eServices. Projects address the deployment of environmental applications and services as one of several areas of common interest for online public services; b) the eContent programme which is a market-oriented programme supporting the production, use and distribution of European digital content, including its linguistic diversity. Access to and use of geographical information is a key theme, where environment and risk management are important end-user applications. Geographical and spatial data remains a key priority under the follow-on programme, eContentplus (2005-2008).

\subsection{3 Current R\&D Activities in ICT and Environment}

\section{Risk Planning and Forecasting}

Until recently risk management components were developed independently by a vast range of institutions and organisations. Exchange of relevant information needed in dealing with risk is too often hindered by administrative and legal boundaries as well as lack of interoperability on the technical side. Recently, the Commission proposed a new regulation, which aims at harmonising geo-spatial information across the EU called INSPIRE (www.ec-gis.org/e-esdi/). This offers a unique opportunity for a major overhaul in disaster preparedness, contingency planning as well as community involvement in risk reduction. Current projects such as ORCHESTRA (www.euorchestra.org) and WIN (www.win-eu.org) are working on service architectures for risk management based on open standards and fully compliant with the INSPIRE regulation (see also Table 1).

This approach should not only dramatically reduce the cost of building and maintaining risk management applications, but it will also allow for the appropriate handling of systemic risk or domino effects.

\section{Crisis Management Operations}

It appeared that civil protection authorities did not benefit as much as other professionals from the new Information and Communication Technologies. Most of these public bodies are poorly equipped, and since this market is rather small, providers companies are slow to invest in up-to-date applications and equipment. This was the one of the reasons for the EU to promote this field. It was also perceived as an opportunity to improve equipment interoperability, to allow different emergency actors, possibly belonging to different regional or national European authorities, to work jointly in case of large-scale disasters.

Crisis management operations are based on a three-level architecture concept: the coordination and command centre supported by function-specific control rooms, the mobile command centres, and the field crew. The function-specific control rooms host the local management and interfaces with auxiliary functions (technical and scientific support, short-term forecasting, meteorological office, emergency health care, public utilities, damage assessment, etc.). The reporting is made to the upper level, the coordination centre, which is located on the local, regional or national government premises, depending on the size of the crises, with a link to the crisis centre of the EC in case of major disaster.

\section{Priorities for Future Work}

Future research will focus on the integration of a wide range of sensors (in-situ, airborne, and satellite) to provide full information awareness for risk planning and 
emergency management. It will also promote the integration of secure, dependable public safety communication systems including ad-hoc broadband networks for emergency operations and alert networks.

To demonstrate its particular interest on the subject, In February 2005, Information and Media DG established a new Unit ICT for the Environment in order to address more efficiently ICT research related to environmental challenge

\section{Information Society Policy Link: Concrete results related to Environment}

On the initiative web site [3] a number of selected Policy cases are demonstrated for all areas including EU Environment policies. A detailed presentation of the selected Policy Cases is given on Table 1. For each policy case are indicated the following elements:

- Project Identification (name, EC code, webpage);

- Policy Area (policy domain e.g. air quality for environmental policy);

- Related policy measure (EU major programmes, references to EU Communications, Directives, Ministerial conferences proceedings etc.);

- Beneficiaries (in both EU and national/regional level);

- Expected impact (concrete impact on policy making or policy monitoring process).

\section{Concrete (Results Policy Cases) Related to Environment}

Table 1 presents a synopsis of Information Society projects impacting EU Environmental Policy identified and analyzed in 2004-2005.

Table 1: Information Society projects impacting EU Environmental Policy

Part I: Policy Area and Related policy Measure

\begin{tabular}{|c|c|c|}
\hline Project Identification & Policy Area & Related policy measure: \\
\hline $\begin{array}{l}\text { APNEE-TU IST-2001- } \\
34154 \text { (FP5) } \\
\text { www.apnee.org/en/index.ht } \\
\text { m }\end{array}$ & $\begin{array}{l}\text { Air quality } \\
\text { Early warning of } \\
\text { environmental } \\
\text { hazards }\end{array}$ & $\begin{array}{l}\text { Communication on Clean Air for Europe } \\
\text { (CAFE) Programme (COM(2001 } 245 \\
\text { final); Framework Directive } 96 / 62 / \mathrm{EC} \text { on } \\
\text { ambient air quality assessment and } \\
\text { management; Decision } 97 / 101 / \mathrm{EC} \text { on } \\
\text { exchange of information and data on } \\
\text { ambient air quality }\end{array}$ \\
\hline $\begin{array}{l}\text { DISMAR: IST-2001-37657 } \\
\text { (FP5) } \\
\text { Web:www.nersc.no/Project } \\
\text { s/dismar }\end{array}$ & $\begin{array}{l}\text { Marine protection } \\
\text { Open standards for } \\
\text { marine risk } \\
\text { management }\end{array}$ & $\begin{array}{l}\text { INSPIRE initiative; Decision No } 2850 \text { of } \\
20 / 12 / 2000 \text { on cooperation in the field of } \\
\text { accidental or deliberate marine; Pollution }\end{array}$ \\
\hline $\begin{array}{l}\text { EGERIS: IST-2000-28345 } \\
\text { (FP5) } \\
\text { Web: www.egeris.org }\end{array}$ & Risk management & $\begin{array}{l}\text { INSPIRE initiative; Galileo } \\
\text { Joined-up emergency response }\end{array}$ \\
\hline $\begin{array}{l}\text { Project Identification } \\
\text { HARMONOISE: IST- }\end{array}$ & $\begin{array}{l}\text { Policy Area } \\
\text { Noise }\end{array}$ & $\begin{array}{l}\text { Related policy measure: } \\
\text { Directive } 2002 / 49 / \mathrm{EC} \text { on the }\end{array}$ \\
\hline
\end{tabular}


2000-28419 (FP5)

Web: www.harmonoise.nl HEAVEN: IST-1999.

11244 (FP5)

Web: http://heaven.rec.org

MINEO: IST-1999-10337

(FP5)

Web: www.brgm.fr/mineo

ORCHESTRA IST-2002-

511678 (FP6)

Web: www.eu-

orchestra.org

OSIRIS: IST-1999-11598

(FP5)

Web: www.ist-osiris.org

SUMARE: IST-1999-

10836 (FP5) Web:

www.mumm.ac.be/

SUMARE

eSEVESO (eTEN)

Web: www.e-seveso.net
One voice on noise

assessment

Air quality

HEAVEN

controlling pollution

through real time

traffic management

Land use MINEO:

Mitigating mining

impacts

Risk management

for Europe

Civil protection

Timely responses to

flood risks

Marine protection

Sustainable marine

environments

Chemicals cost-

effective

compliance
Assessment and Management of

Environmental Noise

Clean Air for Europe Programme (CAFÉ)

Directive on Air Quality Assessment and

Management (Framework Directive)

(1996/62/EC) and associated Daughter

Directives

Directive on the Assessment and

Management of Environmental Noise

(2002/49/EC)

Communication: Towards a Thematic

Strategy on the Urban Environment

(COM(2004)60);

Directives on environmental impact

assessment and land use

INSPIRE initiative

Global Monitoring for Environment \&

Security (GMES)

Communication: Reinforcing the Civil

Protection Capacity of the European

Union (COM(2004) 200)

The Water Framework Directive

2000/60/EC; Directive on Quality of

Bathing Water (COM(2002)581)

Directive on the Control of Major-Accident Hazards (96/82/EC)-(the 'Seveso II

Directive'); EU Proposal on Chemicals Policy (REACH)

Table 1: Part II (Beneficiaries and Expected impact)

\begin{tabular}{|c|c|c|}
\hline Ientification & Beneficiaries & Expected impact \\
\hline $\begin{array}{l}\text { APNEE-TU IST-2001- } \\
34154 \text { (FP5) } \\
\text { www.apnee.org/en/index.ht } \\
\text { m }\end{array}$ & $\begin{array}{l}\text { Environmental } \\
\text { agencies; } \\
\text { meteorological } \\
\text { services; local } \\
\text { administrations }\end{array}$ & $\begin{array}{l}\text { Ability to 'narrowcast' environmental } \\
\text { warnings or advice to citizens most at ris }\end{array}$ \\
\hline $\begin{array}{l}\text { DISMAR: IST-2001-37657 } \\
\text { (FP5) } \\
\text { Web:www.nerse.no/Projects } \\
\text { / dismar }\end{array}$ & $\begin{array}{l}\text { : Environmental } \\
\text { agencies and civil } \\
\text { protection } \\
\text { authorities }\end{array}$ & $\begin{array}{l}\text { Better monitoring and management of } \\
\text { marine environments }\end{array}$ \\
\hline $\begin{array}{l}\text { EGERIS: IST-2000-28345 } \\
\text { (FP5) } \\
\text { Web: www.egeris.org }\end{array}$ & $\begin{array}{l}\text { Civil protection \& } \\
\text { emergency services }\end{array}$ & $\begin{array}{l}\text { More effective management of civil } \\
\text { emergencies and disaster response }\end{array}$ \\
\hline $\begin{array}{l}\text { HARMONOISE: IST-2000- } \\
28419 \text { (FP5) }\end{array}$ & $\begin{array}{l}\text { Environmental } \\
\text { regulators: citizens }\end{array}$ & $\begin{array}{l}\text { Harmonised approach to the assessment } \\
\text { of environmental noise levels }\end{array}$ \\
\hline
\end{tabular}

Web: www.harmonoise.nl 
HEAVEN: IST-1999-11244

(FP5)

Web: http://heaven.rec.org

MINEO: IST-1999-10337

(FP5)

Web: www.brgm.fr/mineo

ORCHESTRA IST-2002-

511678 (FP6)

Web: www.eu-orchestra.org

OSIRIS: IST-1999-11598

(FP5)

Web: www.ist-osiris.org

SUMARE: IST-1999-10836

(FP5) Web;

www.mumm.ac.be/

SUMARE

ESEVESO (eTEN)

Web: www.e-seveso.net
Municipal \& local

administrations

responsible for

Local

administrators;

environmental

regulators, industry

Civil protection

authorities,

environmental

agencies

Flood prevention

authorities;

citizens in flood-

prone areas

Environmental

agencies; marine

industries

Industry, especially

SMEs; regulatory

authorities
Monitoring of vehicle related pollution in near real-time and prediction of future trends

Better assessment of environmental status and impact in European mining areas, as well as applications to other environmental problems

More effective trans-boundary risk

management

More effective management of flood risks and inundation events

Better and more detailed monitoring of marine environments

More cost-effective compliance with

EU legislation

\section{Information Society Policy Link: The next steps}

In order to better demonstrate impact of IS projects and initiatives on other EU policy areas the instrument of Policy Interfaces and Policy Workshops have been launched in 2005. Policy Interfaces are structured meeting between Information Society and Media Directorate-General and other EU services with the aim to inform Policy DGs about INFSO plans for RTD activities in ICT, listen to their specific requirements for ICT research and ensure that results from INFSO-funded research projects and other activities can support the implementation of EU policies to the fullest possible extent.

Under this framework IS Policy Workshops i.e. a working event/conference on a particular theme are organized in cooperation with INFSO units, one or more thematic sub -groups or DGs. First themes proposed are: Employability of ICT Professionals, Beyond the Internet, E-resources for SMEs, E-Collaboration for Public Administrations, eInclusion/ eUser workshops.

The next phases of the Information Society Policy Link initiative will focus on three areas:

- Refinement of existing cases e.g. review existing data collections - revisit findings (FP5); processing new information (mainly 1ST FP6; eTen; eContent); new wave of Policy Cases for each of 20 thematic areas

- Expansion of coverage by establishing contacts with remaining DGs and run Policy Interface meetings with DGs; launch special actions for EP \& pilot National Parliaments, MS Administrations

- Promotion and in particular disseminate first findings to EU policy makers; Targeted promotions campaign; Launch new publications on new Policy 
areas and cases; Organize a number of IS Policy Workshops; Pilot actions for MEP, Nat. Parliaments and Administrations

Furthermore synergies will be sought between DG INFSO coordinated related information services and projects such as IST results and Information Society Policy Link and targeted promotional efforts to increase societal awareness on impact of ICTs in economy and society.

\section{Conclusions}

The European Commission is supporting ICT research since 20 years with considerable resources devoted not only on IT technologies and communications but also to important applications notably in the areas of Public Health and Environment. Project results from the most recent Framework Programmes (FP4 and beyond) have demonstrated that even if selected on their policy relevance but mainly for its scientific merit, numerous ICT EU funded projects have considerable impact on other EU policies such as public health, environment, security, regional policy etc.

The first results of the DG Information Society and Media Information Society Policy Link initiative show that practically all policy areas could benefit from such project results in particular in integrating new concepts in coming policy initiatives, monitoring the implementation of existing regulation e.g. pollution levels, biometric controls etc. Communication and awareness raising actions should be reinforced in order to inform policy makers at all levels and influence the decision making process.

EU is devoting now a lot of resources on RTD and deployment actions impacting all policies and environment in particular. It is supporting the implementation of the research results through various initiatives such as eEurope, specific deployment actions, Action plans and Communications, Ministerial and high-level conferences and policies related to beneficial take-up ICTs. Information Society and Media DirectorateGeneral in close cooperation with other EC services also contributes to major EU environment related large scale activities such as GMES and INSPIRE.

Regarding environment and ICT future research will focus on the integration of wide range sensors (in-situ, airborne, and satellite) to provide full information awareness for risk planning and emergency management. It will also promote the integration of secure, dependable public safety communication systems including adhoc broadband networks for emergency operations and alert networks. Finally, Information Society Policy Link initiative will in the near future intensify efforts to cover the whole spectrum of EU policies with meaningful policy cases - promising ICT project results positively impacting all EU policy areas.

\section{References}

1. IS Portal: http://europa.eu.int/information_society: Information on all policy initiatives and actions covering the Information Society and Media area.

2. IST Results: http://istresults.cordis.lu/index.cfm: Information service promoting RTD results emanating from the IST programme

3. ISPL: http://europa.eu.int/information_society/activities/policy_link/index_en.htm

4. 6th EAP: http://europa.eu.int/comm/dgs/environment/index_en.htm 


\author{
Abbreviations \\ EU: European Union; EC: European Commission; \\ ICT or ICTs: Information and Communications Technologies \\ DG INFSO: Information Society and Media Directorate-General \\ RTD: Research and Technological Development \\ MI: Medical Informatics \\ IST: Information Society Technologies (research programme) \\ FP: Framework Research \\ EP: European Parliament \\ DG: Directorate-General \\ ESA: European Space \\ INSPIRE (INfrastructure for SPatial InfoRmation in Europe) \\ Environment 2010: Our Future, Our Choice \\ Environment Action Programme (EAP)
}

\title{
Acknowledgements
}

We cordially thank our colleagues in DG Information Society and Media, C.2 Unit: Strategy and Policy for ICT research and other thematic Units (G.5: ICT for Environment) for their contributions in this paper. 